\title{
QUEEN'S
UNIVERSITY
BELFAST
}

\section{In and out of home care decisions: The influence of confirmation bias in developing decision supportive reasoning}

Spratt, T., Devaney, J., \& Hayes, D. (2015). In and out of home care decisions: The influence of confirmation bias in developing decision supportive reasoning. Child abuse \& neglect, 49, 76-85.

https://doi.org/10.1016/j.chiabu.2015.01.015

\section{Published in:}

Child abuse \& neglect

\section{Document Version:}

Peer reviewed version

Queen's University Belfast - Research Portal:

Link to publication record in Queen's University Belfast Research Portal

\section{Publisher rights}

(c) 2015 Elsevier Ltd.

This manuscript version is made available under the CC-BY-NC-ND 4.0 license http://creativecommons.org/licenses/by-nc-nd/4.0/, which permits distribution and reproduction for non-commercial purposes, provided the author and source are cited.

\section{General rights}

Copyright for the publications made accessible via the Queen's University Belfast Research Portal is retained by the author(s) and / or other copyright owners and it is a condition of accessing these publications that users recognise and abide by the legal requirements associated with these rights.

Take down policy

The Research Portal is Queen's institutional repository that provides access to Queen's research output. Every effort has been made to ensure that content in the Research Portal does not infringe any person's rights, or applicable UK laws. If you discover content in the Research Portal that you believe breaches copyright or violates any law, please contact openaccess@qub.ac.uk. 


\title{
In and out of home care decisions: The influence of confirmation bias in developing decision supportive reasoning
}

\author{
ABSTRACT \\ The aims of this study were to identify the themes Social Workers regard as \\ important in supporting decisions to remove children from, or return them to, the \\ care of their parents. To further elicit underlying hypotheses that are discernible in \\ interpretation of evidence.
}

A case study, comprising a two-part vignette with a questionnaire, recorded demographic information, child welfare attitudes and risk assessments, using scales derived from standardised instruments, was completed by 202 Social Workers in Northern Ireland. There were two manipulated variables, mother's attitude to removal and child's attitude to reunification two years later. In this paper we use data derived from respondents' qualitative comments explaining their reasoning for in and out of home care decisions.

Some $60.9 \%$ of respondent's chose the parental care option at part one, with $94 \%$ choosing to have the child remain in foster care at part two. The manipulated variables were found to have no significant statistical effect. However, three underlying hypotheses were found to underpin decisions; (a) child rescue, (b), kinship defence and (c) a hedged position on calculation of risk subject to further assessment.

Reasoning strategies utilised by social workers to support their decision making suggest that they tend to selectively interpret information either positively or negatively to support pre-existing underlying hypotheses. This finding is in 
keeping with the literature on 'confirmation bias'. The research further draws attention to the need to incorporate open questions in quantitative studies, to help guard against surface reading of data, which often does not 'speak for itself.'

Keywords: Decision making, professional judgment, confirmation bias.

\section{Introduction}

Decisions with regard to when a child should be removed from the care of their parents and when they should be returned are of central importance as a public issue with regard to professional practice. In this paper we employ data from an international study of decision making to explore the ways in which social workers in one part of the United Kingdom, Northern Ireland, develop rationales to support in and out of home care decisions; in doing so, providing indication of the presence of confirmation bias.

\section{The Policy Context}

There is a concern among politicians and policy makers in the United Kingdom that public services are often not delivered in a consistent and reliable fashion. The experience of being a recipient of state intervention is often viewed as being unequal and arbitrary, with particular experiences subject to the vagaries of what has been termed, a 'postcode lottery' (Commission on Funding of Care and Support, 2011; Munro, 2011). Whilst access to health care, the latest treatments and provision of care in old age are all significant issues that are of import to everyone, less attention has been given to whether access to child welfare services are subject 
to the same lack of consistency. This is especially the case in relation to services relating to the protection and care of very vulnerable children. This is particularly important in relation to the critical issue as to when, and under what circumstances, a child should be removed from the care of their parents and into the care of the state. Commentators have noted wide variations evident in admission rates across the UK (McSherry et al., 2010).

During the latter part of the last century considerable effort was expended through the Quality Protects Programme (Department of Health, 1998) to introduce a system of benchmarking performance across different parts of the statutory child welfare system in England. This was in recognition of the importance of ensuring that when decisions are being made that infringe upon the private sphere of family life, that the intrusion was both warranted and proportionate, and that similar standards were being applied in different local authorities (Devaney, 2004; Thorpe, Denman \& Regan, 2011).

A key factor in this debate has been the process of decision making by individual practitioners. Decision making is complex, and fraught with both intellectual and emotional challenges (O'Sullivan, 2011). As noted by O'Connor \& Leonard (2013: 2), 'decision making incorporates multi-layered negotiation, applications of professional judgement and interpretation of knowledge and evidence'. This takes place within an interconnected set of ethical, legal and policy contexts involving the views and opinions of service users, other professionals and service systems such as the courts. The act of making a decision and decision making processes have been subject to scrutiny through formal reviews and inquiries when there has been a poor outcome in particular cases, for example, the review by Lord 
Laming into the death of Peter Connelly (Laming, 2009). These have highlighted a number of interconnected issues that influence decision making, including the education and training of social workers (Croisdale-Appleby, 2014; Narey, 2014) and the particular context within which individual practitioners work (Munro, 2011).

Policy makers, however, have tended to veer towards introducing systems that collect large amounts of data about how the system operates (such as referral rates), and outputs (the numbers of children subject to child protection interventions). Less attention has been given to the process of making decisions, rather than the outcome of those decisions. Empirical studies of social work decision making have previously been undertaken in the UK in an attempt to understand the factors influencing practitioner decision making (Spratt, 2000; Platt, 2006; Hayes \& Spratt, 2009; 2014). Such research has demonstrated that professional decision making is not purely a matter of applying knowledge to data in a rational manner, but rather represents an amalgam of subjective processes in determining how facts are understood, manipulated and acted upon.

\section{Professional Decisions and Confirmation Bias}

Professionals working in the field of child welfare are often required to make decisions relatively quickly, in accordance with timescales set out in policies and procedures, and in situations where the information available to them emanates from disparate sources, is contested, or is incomplete. The decision a professional reaches flows from the assessment process during which information and evidence is gathered about the situation of the child and family and the professional attempts to make sense of it. This sense-making process leads to a professional judgement 
being made which involves the evidence being considered "...in the light of professional knowledge to reach a conclusion or recommendation" (Taylor, 2010: 165) and which informs the decision regarding what action or intervention is required. The formation of this judgement takes place along a continuum between intuitive (or 'gut feeling') and analytical reasoning which Munro, (2008: 2) describes as follows:

"At one extreme, analytical reasoning is formal, explicit and logical. It is associated with mathematics and rigorous thought, where every step in the argument is spelled out. In contrast, intuition is non-verbal, swiftly reaching a conclusion on the basis of largely unconscious processes."

Although these two types of reasoning are often presented as polar opposites, Munro (2008) argues that both have an important role to play in the processes of assessment, judgement formation and decision making. This view is shared by a number of commentators (Reder \& Duncan, 2004; Helm, 2010; Holland, 2011; O'Sullivan, 2011), it being argued that both approaches need to be integrated and balanced to enable workers to reason effectively. For example, Brannan (2014: 163) argues that overly intuitive approaches lack rigour whereas overly analytical approaches may lack action; "...the so-called paralysis by analysis."

The lack of rigour commonly associated with intuitive approaches stems from the use of heuristics, or 'cognitive rules of thumb' (Collins \& Daly, 2011: 31), which simplify the reasoning process by enabling us to generalise from previous knowledge of similar situations. Munro (2008) notes that heuristics are effective in our day-today lives but do lead to biases and errors in our judgements and decision making. In terms of child welfare practice, one of the most dangerous biases that can result 
from an overly intuitive approach to reasoning is confirmation, or confirmatory bias (Gambrill, 2005; Munro, 2008; Burton, 2009) which is also referred to variously as 'verificationism' (Scott, 1998; Holland, 2011), 'fixed thinking' (Brandon et al., 2009), or 'adjustment bias' (Taylor, 2010). These terms all relate to the general human tendency to form a preferred explanation quite early in the consideration of a situation and to continue with that explanation even in the face of new information that suggests that it is flawed or incorrect. Once this preferred explanation has been formed, emerging information is unconsciously selected and weighed in a way that ensures that the favoured explanation will be supported rather than challenged. As Nickerson (1998: 175-176) outlines, confirmation bias involves:

"...unwitting selectivity in the acquisition and use of evidence... and unwitting molding of facts to fit hypotheses or beliefs... without intending to treat evidence in a biased way or even being aware of doing so..."

In the context of assessment, judgement formation and decision making by child welfare professionals, this type of bias can have deleterious consequences if practitioners persist in their initial explanations and judgements, seeking out only the information that supports their intuition, and do not review these in the light of either new evidence or differing views of the existing information. As Helm (2010) observes, confirmation bias can lead to either an under-estimation or overestimation of the degree of risk to a child. Professionals may, for example, continue to believe that the parent is providing adequate care for the child even though there are reports of concerns about the child and injuries to them. The death of baby Peter Connolly in the United Kingdom (Haringey Local Safeguarding Children Board, 2009) provides an example of a situation whereby professionals from a range of 
agencies appeared to develop an early judgement in relation to his circumstances that was resistant to change with Turney et al., (2012: 89) noting that:

"Evidence (head injury with no satisfactory explanation, sustained by a baby) that in other circumstances might have alerted practitioners to the dangers of the situation was interpreted in a way that failed to challenge the view of Peter's mother as a concerned parent, apparently working cooperatively with the different professionals involved."

At the other end of the spectrum, however, professionals may also wrongly judge parents to have been abusive and fail to acknowledge evidence that challenges this belief resulting in potentially devastating consequences for the family (Davies, 2011).

Munro (2008) outlines a number of techniques that professionals may employ unconsciously in order not to acknowledge evidence that challenges their intuition. Firstly they may engage in 'avoidance' so, for example, if they assume that the parent is telling the truth they may fail to check their account of events and uncover evidence of deceitfulness. Secondly, they may 'forget' contradictory evidence so, for example, if the professional views parents as being neglectful they are more likely to remember occasions when they have seen the children appearing unkempt and unhappy but "...memories of home visits when the children looked clean and warm, or the house was in good order, will not be so readily thought of" (Munro, 2008: 150). Thirdly, professionals may 'reject' challenging information based on their perception of the motivation or competence of the person providing the information. Parents, for example, may be viewed as being untruthful, children as lacking sufficient understanding and being too young to be given credence to, 
neighbours and relatives as being malicious, and other professionals as being inexperienced. Finally, information may be 'reinterpreted' so that it fits the professional's judgement rather than countering it.

The potential for confirmation bias does not, however, mean that professionals should abandon intuitive reasoning. Firstly, this would not be possible and, secondly, it has advantages. As Helm (2010: 150) argues:

"Using intuition is not the problem. Indeed it can help us generate flashes of inspiration and pick out ideas that our rational analysis could not. The problem is that we may not then take these intuitive thoughts back to the workshop of analytical thinking and therefore not test our hypotheses with sufficient rigour." As Munro (2008) argues, aiming to avoid confirmation bias is unrealistic and the focus should, rather, be on detecting it and developing strategies to minimise its impact on professional decision making.

\section{Method}

\section{Background}

The research reported here is derived from a four country (Northern Ireland, Israel, Spain and the Netherlands) study in decision making in cases of child maltreatment. An extensive (three page) case vignette was designed, featuring parents with three children, the oldest of whom (Dana - age 7) has been referred to social workers by her primary school teacher because of concerns that she has physical injuries. Upon assessment it is found that the family lack support, face social and economic difficulties and there is indication that Dana's physical and emotional needs are not being met. 
A case vignette was adopted as this factorial survey method has a long history of use in decision making studies (Giovannoni \& Becerra, 1979), enabling the study of the way 'that professionals make decisions in real life [and providing] a unique capability to investigate the effect of multiple factors in complex decisions' (Taylor, 2006: 1187). Whilst seeking to replicate actual decision making the methodology is, of course, 'emotionally decontextualized' (Spratt, 2000: 607) from real world environments wherein other variables such as time pressure and the influence of previous case outcomes will influence decisions.

The questionnaire accompanying the case vignette was designed by the international study team to collect information on the personal and professional backgrounds of respondents, examine their child welfare attitudes and risk assessment, using scales derived from standardised instruments. In particular we were interested in decisions involving possible removal of Dana from and return to, parental care. The quantitative findings from this study are in the process of being reported (Benbenishty et al., 2014, currently under review). In this paper we use data derived from the Northern Ireland strand of the study in the two text boxes within the questionnaire, where respondents were asked to provide reasons for in and out of home care decisions.

In concentrating our attention on respondents from one country we are essentially seeking to study in depth the reasons offered in support of decision making to elucidate key themes and offer explanations within the context of psychological theory. A study involving participants across the four countries would have the effect of introducing a much greater number of cultural context variables 
which would limit the potential to investigate psychological phenomena and produce rather, a focus on cross cultural comparisions.

\section{Participants}

The 202 professionals in the Northern Ireland sample were all professionally qualified social workers with experience of working with families and children. Under the Children (Northern Ireland) Order 1995 (the governing legislation) supportive and child protection functions are not seen as separate. Therefore social workers may seek to achieve further protection of the child by means of providing services to families to ameliorate stress. Conversely, those social workers whose primary focus is the support of families will be mindful of, and watchful for, those situations where the constellation of circumstances leaves the child either vulnerable to, or subject to, maltreatment.

The process of recruiting the social workers involved seeking permission from social work agencies (both government and non-government organisations) to distribute questionnaires to qualified social workers with experience of working with families and children. In addition, a research dissemination conference was organised at Queen's University Belfast and participants who met the selection criteria were given the opportunity to complete the questionnaire. Participation in the study was incentivised by an invitation to enter a draw to win an iPad via receipt of respondents email address (which could not be cross referenced with the anonymised questionnaire). 
Ethical permission for the study was sought and obtained from the ethics committee of the School of Sociology, Social Policy and Social Work at Queen's University Belfast.

\section{Procedure}

Participants were presented with one of four randomly assigned versions of the case study. As part of the study sought to explore to what extent, if any, two variables impact on in and out of home care decisions we presented the vignette in two parts, with the first manipulated variable in part one and the second in part two. The first part described conditions at initial referral, the manipulated variable being the mother's attitude towards removal. In one version of the vignette the mother voiced strong objection to removal to a foster family, stating: "no way will anyone touch my family and I'm ready to go to court on it." In the alternative version the mother did not voice an objection stating: "If you think this is better for the family, I am willing to try." Respondents were asked to indicate: Which type of intervention would you recommend for this case? Please choose the most suitable intervention from the following options (from a menu ranging from home based services through voluntary to court mandated reception into state care). Respondents were requested to give reasons for their choices in Text Box 1.

In part two of the vignette, it was revealed that, following a child protection case conference, the actual decision taken had been to place Dana in foster care, with the agreement of her parents. Dana has been in foster care for two years where she has made good progress. There have not, however, been comparable changes in her family, who refused to accept the treatment that was offered them 
and consistently ignored Dana and the foster family. In the follow-up discussion after two years, it became clear that the mother is vigorously demanding that Dana be returned home and "is ready to go to court to get her back." This part of the vignette was varied in relation to the child's attitude towards reunification. In one version respondents were informed that; 'In a number of meetings with Dana the assessment was that she was not interested in returning to her biological family because she felt good in the foster family and did not feel that she had a good connection with her family and that they ignored her.' In the alternative version, respondents were informed that; 'In a number of meetings with Dana the assessment was that she was interested in returning to her biological family, despite the fact that she felt good in the foster family.' Respondents were asked to indicate: Which type of intervention would you recommend for this case? Either: 'reunifying the child with her biological family while continuing working with the foster family, the biological family and the child' or: 'keeping the child with her foster family while continuing working with the foster family, the biological family and the child.' Respondents were requested to give reasons for their choices in Text Box 2.

The data was then then subjected to summative content analysis. This technique is used to identify the frequency of words or phrases in the text. Once quantified these are then analysed to identify recurring themes and elucidate their meaning (Potter \& Levine-Donnerstein, 1999). Automatic text content analysis is sometimes used to assist in the quantification process. However, as Grimmer and Brandon point out, automated content analysis methods do not 'eliminate the need for careful thought by researchers nor remove the necessity of reading texts' (2013: 270). While this method may be helpfully employed when very high volumes of text 
require analyses, especially in transforming text into quantitative data, given the modest scale of this study the manual reading of the 400 text boxes (each containing on average between one and two sentences) was possible. To reduce the potential for researcher bias in the identification of themes and numeric representation of these, the work of one of the authors, who undertook the initial coding and analysis, was subject to review by the other two authors. This ensured that identification of themes had integrity with the textual content and that their numeric representation were accurate.

The first step in this process was to collate all the qualitative data from the two text boxes ( 1 and 2 ) and code to cross reference with decisions on in and out of care options. The qualitative data was then read and reread to permit the identification or recurring words and phrases. Once frequencies had been established it was possible to identify numerically dominant themes. At this stage those themes with low cell counts, i.e. comments made by ten respondents or less, were eliminated. Further analysis of the textual data was then undertaken to illuminate the types of supporting rationales employed by each of the respondent groups with respect to their decision-making.

\section{Analysis}

There were four themes identified representing responses in the Text Box at Decision 1 and five in the text box at Decision 2 . We report theme frequencies with respect to four respondent groups, $A, B, C$ and $D$ explaining decisions to either remove or keep the child at home (Text Box 1) and whether to return the child home or have her remain in care (Text Box 2). 
The four respondent groups (approximately 50 in each) are represented thus:

A -/- Mother uncooperative/ about admission to care; child negative re reunification B -/+ Mother uncooperative/ about admission to care; child positive re reunification C +/+ Mother cooperative/ about admission to care; child positive re reunification D +/- Mother cooperative / about admission to care; child negative re reunification

\section{Results}

\section{Demographics}

With regard to demographic characteristics of the sample: the respondents were predominantly female (80\%). We recorded ages in bands, with $96 \%$ being aged 25 years or older. The breakdown revealed that $17 \%$ were in their 20 s, $28 \%$ in their 30 s, with $53 \%$ aged $40+(2 \%$ missing). Sixty per cent of respondents were parents. Only $3 \%$ of respondents were newly qualified social workers; $37 \%$ had between 1 and 6 years' experience, $20 \%$ between 7 and 12 years, with the remaining 34\% having more than 12 years (6\% missing). Seventy three per cent of respondents were employed by Health and Social Care Trusts (local government agencies with primary responsibility for child protection), with the remainder employed by other governmental and non-governmental organisations working with children and families, all within Northern Ireland.

\section{Quantitative Analysis}

At the first decision point in the Case Study, where Dana is still in the care of her parents but experiencing considerable risks to her health and welfare, a majority of respondents from Northern Ireland (60.9\%) were against admitting Dana into foster 
care. The first manipulated variable, of the mother supporting or alternatively objecting to reception into foster care, had no statistically significant effect on this decision. At the second decision-making point, where Dana has been in foster care for two years, a large majority of respondents (94\%) supported her remaining in care. The second manipulated variable, of Dana either wishing or not wishing to return home also had no statistically significant effect on this decision.

\section{Qualitative Analysis}

In undertaking an analysis of the supporting textual qualitative data our aims are to better understand how respondents considered the manipulated variables in their decision making, what additional themes they identified as important in informing their decisions and the reasoning strategies they employed in decision making.

\section{Decision 1 -Remove to foster care or remain at home?}

With regard to comments made in response to decision 1 , it is evident that respondents were concerned with four themes: 1 the importance of Parental Agreement; 2 use of Child Protection Procedures; 3 involvement of the Court; 4 undertaking an Assessment and Provision of Services. The frequencies of responses are recorded in Table 1, showing the numbers of responses made in relation to each theme broken down by the four respective groups. N.B. some respondents gave more than one response. 
Table 1: Themes and frequencies by group: Decision 1

\begin{tabular}{|l|l|l|l|l|}
\hline & $\begin{array}{l}\text { 1 Parent } \\
\text { Agreement }\end{array}$ & $\begin{array}{l}\text { 2 Child } \\
\text { Protection } \\
\text { Procedures }\end{array}$ & 3 Court & $\begin{array}{l}\text { 4 Assessment } \\
\text { / Services }\end{array}$ \\
\hline A - & 3 & 14 & 14 & 31 \\
\hline B - & 2 & 5 & 14 & 25 \\
\hline C + & 11 & 7 & 5 & 46 \\
\hline D + & 9 & 6 & 4 & 40 \\
\hline
\end{tabular}

The responses at decision 1 were characterised by marked differences in frequencies, in relation to some of the identified themes, between the four groups. When we combine respondents from A -/B - groups (mother objected to Dana's removal), they were less likely ( $n=31$ ) to cite the need for further assessment than were $C+/ D+$ respondents $(n=45)$ (mother supported removal). The opposite tendency is evident in the invocation of multidisciplinary formal child protection procedures with $21 \mathrm{~A}$-/B - respondents favouring this action (although A predominates) compared to $13 \mathrm{C}+/ \mathrm{D}+$ respondents. Similarly, $28 \mathrm{~A}$-/B respondents cited a need to involve the court, whilst only $9 C+/ D+$ respondents saw this as important. Conversely, and not surprisingly, $20 \mathrm{C}+/ \mathrm{D}+$ respondents cited a need to promote parental agreement, whilst only $5 \mathrm{~A}$-/B - respondents identified this as an important factor. Finally, the same pattern is true for the further assessment/provision of services; here $86 C+/ D+$ respondents cited a need for this compared to $56 \mathrm{~A}$-/B - respondents.

What do these variations in frequency of response indicate? Firstly, that the manipulated variable of Dana's mother either objecting or not objecting to her removal does have some influence in relation to thematic response frequency. Secondly, the preferences for the formal child protection procedural and court mandated responses within A -/B - groups are explicable in the context of developing 
an evidential case and professional consensus within which to seek a legal mandate to act against the wishes of Dana's mother. Where the wishes of parents are in accord with the professional view, as is the case with the $C+/ D+$ groups, then there is greater emphasis placed on undertaking further assessment and providing services to promote improvement of the home situation. Thirdly, the analysis of comment frequencies demonstrates something of the prevailing concerns of each group with regard to what themes they consider important in explaining and supporting their decisions.

\section{Comment Analysis - Decision 1}

Having deduced what themes practitioners considered important, we now turn to examining why they considered them important. The themes require further textual analysis. This provides very rich material; enabling us to examine both frequency and content to illuminate how professionals interpret data to support decisions they, in some cases, may have already made. Consequently, the next stage in analysis involved a careful consideration of the comments made to seek to illuminate their meanings. We started by examining the theme that identified the first manipulated variable. What rationales did respondents employ in their consideration of the issue of parental agreement/disagreement in relation to Dana's admission to care? Specifically, how did A -/B -groups respond to the objections of Dana's mother to her removal into foster care and conversely, how did C +/D + groups respond to her willingness to have Dana taken into care?

It was evident that those few respondents from A -/B - groups who mentioned parental agreement were concerned to do so because they were looking 
to the future. One who had recommended removal against the mother's wishes was, nevertheless, looking beyond this decision toward a possible reunification strategy: 'The best way is to ensure Dana is in a protective environment while trying to engage parents.... with care plan for rehabilitation home with sufficient engagement in services by parents.' Another respondent who wanted Dana to remain with her parents saw such engagement as a way to involve them with services: 'Attendance at a family centre would be more in spirit of collaborative work with parents.' The most significant point of note here, however, is not with regard to the comments made, but rather to the lack of comments made by A -/B - groups. It is as if the voice of the parent has not been heard or regarded as validated in a situation where there are real and pressing risks to the child that render parental viewpoints of little value. By contrast $C+/ D+$ groups were much more likely to cite the view of the mother to support removal as validating their own decisions. Perhaps surprisingly, this applied in the main to decisions to leave Dana at home, with parental co-operation seen as helping validate this choice. '[The] issue should be addressed further with family initially in attempting to work in partnership in a family support approach.' And; 'A robust safety plan and parental co-operation could prevent admission.' The interesting point to observe is that the mother's willingness to admit the child to foster care, in combination with a case history redolent of abuse and neglect, were not generally regarded as indication that the parental attachments to Dana were not secure and that continued risks might be predicted if Dana were left at home. One respondent from group $\mathrm{C}+$, who did read the mother's co-operation negatively and recommended removal to foster care, put the reason succinctly: 'Because of the mother's attitude and lack of passion for Dana i.e. not fighting to keep her out of 
care.' However, for the majority of respondents, a co-operative attitude with regard to removal was read as an important indicator of future positive engagement with the family, despite the history of the case, which might point to a rather different conclusion. This is essentially a conflation of ideas, where acquiescence with the professional view is seen as a hopeful sign, when it might alternatively, and perhaps more readily, be read as an indication of indifference. The alternative to hope is more usually expressed as despair, but in this case indifference is perhaps a more accurate word, conveying despair in a passive term being a more profound negation of hope.

Turning now to the other themes at Decision 1, it is evident that the need to provide official imprimaturs for decisions weighs more heavily on the minds of respondents from groups $A$ and $B$ where the mother has objected to the foster care option. This is expressed in a duality of requirements to have their decision-making shared with colleagues under the sheltering ambit of child protection procedures and seeking the authoritative support of the courts. In the United Kingdom there is usually no recourse to the courts until such times as co-operative agreements in relation to plans for children have broken down and inherent risks can no longer be managed under prescribed child protection procedures. Such procedures are mandated by government and involve multidisciplinary decision making forums wherein both decisions to establish levels and types of risk and plans to provide services to ameliorate such risks are shared with other professionals. This effectively means that individual social workers are not left to make crucial decisions on their own. A -/B - respondents, lacking parental agreement for possible removal, were more likely therefore, than were $C+/ D+$ respondents, to cite this requirement. One 
respondent stated: 'I would suggest this case is managed within a child protection case conference framework - only where parents fail to co-operate with the child protection plan, should consideration be given to progressing to pre-proceedings [the first step in court proceedings].' The balance suggested between the outworking of child protection procedures and future recourse to court was often expressed as consequent on positive change taking place, in other words the status quo was not seen as acceptable. The following comment captures the idea of a continuum of building interventions, successively triggered by the nature of parental responses: 'Maintain child within family initially under child protection investigation, probably place on register [where such investigations find maltreatment has taken place the multidisciplinary case conference may decide to officially record the child's name on a register of children requiring protection] under potential emotional/physical abuse and neglect and input various services. If no change, attempt voluntary accommodation [once more seeking parental agreement to a foster care placement] and, if not agreeable, [commence] court proceedings.' Comments made with respect to the need for shared decision making also illustrate the underlying view that there are considerable risks to Dana and that if there are no changes to the situation the due processes inherent in the invocation of child protection procedures and courts are likely to lead to recourse to removal to foster care, if not now then at some future date when these processes have played out.

All groups display a hedging tendency with respect to decision making in their frequent mention of the need for further assessment and provision of services. $C+/ D+$ groups, however, mention these themes more frequently. This may represent a further iteration of the tendency for these groups to read parental 
agreement to foster care as a positive foundation upon which further assessment and service provision may be built, together with the risks inherent in not doing so. As one respondent put it: 'Work with the family together. Isolating Dana in a foster family may contribute further to her isolation in the family at this time. Assessing additional services until further plans could be made.' Some respondents were, in fact, quite optimistic in tone: 'This family need a range of service for both the children and parents to further assess and support and provide practical support, and wrap round services for all [!].'

The reasoning underpinning decisions to admit Dana to care or to leave her at home highlight the complex interplay of responses on the part of professionals faced with such difficult decisions. Such reasoning also reflects something of the divide between two alternative and competing discourses in relation to work with families wherein considerable risk to a child may be identified. The first, and larger group, informed by a view that privileges the biological family as the natural and best place to raise children, even where indications to the contrary are present, seeks signs of hope in the ability of parents to respond to supportive services and perceives risks inherent in the provision of foster care. The second, smaller group, whilst respecting the rights of the family, seeks earlier remedy, not ruling out the possibility of reunification, but seeing immediate needs for security and care being best provided by alternative carers. How does the passage of time and circumstance affect such perceptions? The second part of the case study informs participants that Dana has now been in foster care for two years, during which time she has made progress developmentally, but there has been little change in home circumstances. 
Decision 2-Remain in foster care or return home?

The responses at Decision 2 are equally interesting. Five themes are deducible from the data as influencing professional decision-making. These are: 1 the Child's Views; 2 Parental Co-operation; 3 Parents Progress; 4 Child's Progress and 5 Assessment/Services.

The frequencies of responses made in relation to each theme, broken down by the four respective groups, are presented in Table 2 .

Table 2: Themes and frequencies by group: Decision 2

\begin{tabular}{|l|l|l|l|l|l|}
\hline & $\begin{array}{l}\mathbf{1} \text { Child's } \\
\text { Views }\end{array}$ & $\begin{array}{l}\text { 2 Parental Co- } \\
\text { operation }\end{array}$ & $\begin{array}{l}\mathbf{3} \text { Parents } \\
\text { Progress }\end{array}$ & $\begin{array}{l}\mathbf{4} \text { Child's } \\
\text { Progress }\end{array}$ & $\begin{array}{l}\text { 5 Assessment } \\
\text { /Services }\end{array}$ \\
\hline A -/- & 15 & 10 & 20 & 15 & 7 \\
\hline B -/+ & 7 & 13 & 22 & 14 & 18 \\
\hline C $+/+$ & 9 & 14 & 28 & 14 & 15 \\
\hline D +/- & 13 & 16 & 18 & 15 & 13 \\
\hline
\end{tabular}

At Decision 2 the differences in frequency of comments between groups was rather less marked. Where differences were noted it appeared that the variable of Dana's wish to return home $(B+/ C+)$ or not to return home $(A-/ D-)$ was of influence across three of these five themes. Whilst neither the theme of Parental Co-operation nor Child's Progress produced discernible differences between groups with respect to citation frequency, this was not the case with respect to views on Parents Progress, where some difference was evident, $50 \mathrm{~B}+/ \mathrm{C}+$ and $38 \mathrm{~A}-/ \mathrm{D}$ - respectively. In relation to the Child's Views, differences were more marked, with $16 \mathrm{~B}+/ \mathrm{C}+$ and 27 A -/D - citations. In relation to Assessment/Services there were $33 \mathrm{~B}+/ \mathrm{C}+$ and 20 A -/D - citations. 
What do these variations indicate? Of particular interest are the responses given with respect to the theme of the Child's Views. The $B+/ C+$ respondents do not cite this factor as frequently as the A -/D - respondents. We might speculate that the inclusion of the voice of the child as a factor supporting decisions is more likely if the child agrees with the professional's perspective. The reversal of frequencies in response to provision of Assessment/Services may reflect a tacit acknowledgment of the child's wishes being expressed in the requirement for further assessment or provision of therapeutic services to enable Dana to come to terms with separation from her parents.

It is important to remember that whilst a majority of respondents (60.9\%) had at Decision 1 been in favour of Dana remaining at home with her parents, this is now reversed at Decision 2, with a clear majority (94\%) favouring her continuance in the foster care placement. It is as if the period in care has been regarded as a natural experiment, allowing time to evaluative the progress of both parents and child and interpreting the results as supportive (as is reflected in the large majority of comments made) of decisions for Dana to remain in care.

\section{Comment Analysis - Decision 2}

As with Decision 1, each theme at Decision 2 requires further comment analysis. Again, of particular interest are the comments made with regard to the second manipulated variable, the place of the Child's Views in influencing decisions. Those respondents (groups $A$ - and D -) who were informed that Dana did not wish to return home generally used this factor to support their decision that she should not do so, for example one respondent stated that the 'child's voice [is] of paramount 
consideration.' Another that, 'if Dana continued to state that she does not wish to return, then reunification would be ruled out.' The tendency here is to view the child as fully informed and bearing rights of choice as to where they should live. The child's views are regarded as unproblematic because they support the choices made by professionals. This is somewhat reversed in the views of respondents from groups $\mathrm{B}+$ and $\mathrm{C}+$ who were informed that Dana did wish to return home. Whilst they acknowledge the child as having influence on their decision making, they downplay the significance of their choice, using legal language and citing developmental stage as diminishing the child's view. 'Dana is roughly 6 years. She would not be deemed Gillick competent [a legal case referred to in UK law in relation to when a child is deemed by a court as sufficiently mature to have their independent viewpoint acknowledged] and therefore if I was assessing this I could not rely solely on child's wishes and feelings.' Another respondent cited age as a factor: 'Given her age, only limited weight can be given to Dana's interest in returning home.'

With regard to the issue of how the past two years, during which time Dana has been in the care of foster parents, is weighed by respondents, separate evaluations of progress of Dana and her parents are indicated. Almost all the respondents who made comment with regard to the parent's progress did so with negative interpretation, with little residual effect evident in relation to whether the mother had approved or objected to the move to foster care. Rather, the attitudes and behaviours of the past two years are now more readily seen as proof of previously less definitely articulated concerns, as one respondent put it: 'Birth parents have not acknowledged the risks to Dana in the past and have made no changes to accept treatment. Family ignored Dana while she has been in care.' A 
number of respondents intimated that this lack of response signalled a recalibration in the balance between the rights of the parents and the needs of the child, with the weight shifting decisively to the latter: 'As parents do not appear to have acknowledged the concerns and made little effort to change in 2 years to rectify matters, Dana's needs should take precedence.' By contrast the progress of Dana whilst in care is read as confirmation of developmental needs now being met were previously they had been neglected. As one respondent put it: 'Dana is in a stable and secure placement and is developing well.' Attribution to positive change is firmly in the province of good foster parenting, making stark the deficits in natural parents: 'The attachment by Dana to natural parents is a dysfunctional one. Dana has improved in all aspects due to consistent and nurturing parenting.'

One might have anticipated that a natural next step would have been for respondents to introduce a theme of Permanency Planning, given their reading of the results of this two-year natural experiment. In fact this was not the case, and the introduction of the fifth theme of further assessment and service provision reveals that practitioners remain reluctant to translate these judgements into future plans involving permanent separation from parents. This is in spite of their overwhelmingly negative view as to the degree of progress made by the parents in contrast to the obvious gains made by Dana. In other words, the interpretation of Dana's developmental needs being met in the past two years is not extrapolated to a point beyond the immediate future.

As might be expected, however, there was a difference in citation frequency in relation to A -/D - groups for whom Dana's wish not to return home produced less pressure to offer further suggestions as to how the case might be managed in the 
future. $B+/ C+$ groups more likely to feel obligation to do so in the light of Dana's wish to return home and are prepared to undertake further assessment and provide services sometimes based on slim hopes: 'The family/mother's 'vigorous' motivation to have child returned should be utilised to motivate parenting work and achieve change/at least improve contact with child and make future relationship.' The parenthesis on vigorous is original and adds a cynical note to a comment wherein optimism of change is ultimately curtailed to a hope (against hope) of contact leading to deeper relationship. Rather prosaically, and more typically, another respondent reflects on what is necessary, without further comment as to its likely occurrence: 'Parents need to work to make the necessary changes to ensure that Dana would be safe should she return to live with them in the future.'

Comments were interesting for what they do not mention; for example the need for permanent plans to provide for Dana's future needs with regard to identity and stability. And for the rather weary tone of heavily circumscribed hope with regard to views as to the efficacy of further attempts to engage the parents in ways that may be effective in providing for Dana's future care. They reflect a real politic in relation to the child protection system where risks are recognised as, on one hand emanating from dysfunctional families, but solutions too, in relation to what alternative care might provide, also judged as bearing risks. Consequently, even when things are going well, professionals may evaluate their own experiences of the 'system' and be banking short term gains against the probability of future losses.

\section{Discussion}


Whilst our quantitative data did not support an hypothesis that either maternal attitudes to removal to care or the child's wish to return or not to return home have statistically significant effects on decision making, the qualitative analysis of the data reveals how respondents weigh the manipulated variables, how they rationalise decisions and what factors preoccupy them.

\section{Underlying Hypotheses}

It would appear that while respondents approach the case study material with underlying hypotheses already in place, these become apparent in the ways they use case information to inform their judgements. Fox-Harding (1997) has identified the three dominant value positions which inform current thinking in relation to state intervention in family life. These are, firstly, 'child protection', the belief that the care and protection of the child should be the first priority for professionals. Secondly, 'Kinship defence', reflecting a concern to protect the primacy of the biological bond and the rights of families to raise their own child, albeit in some cases requiring state intervention in the form of supportive services to do so. Finally, 'Children's Rights' which is identified as a more modern and growing discourse, reflecting the articles of the United Nations Convention on the Rights of the Child, concerning the duality of rights both to experience family life and to be safe in doing so. The Dana case study was designed in such a way as to permit alternative interpretations of the information. For example it contained information suggesting Dana may have suffered physical maltreatment at the hands of her parents, but lacked confirmatory evidence to support this hypothesis. Respondents therefore were invited to present rationales supporting their interpretation of the information 
available. Such reasoning indicated the presence of three distinct underlying hypotheses (which derive from the Fox-Harding value positions), upon which respondents built interpretations of the case study material to further inform their decisions.

For the two fifths of respondents who decided to admit Dana to foster care the underlying working hypothesis reflects a prevailing concern to protect Dana from maltreatment. The information provided was interpreted as indicating, on balance of probabilities, that she had suffered maltreatment at the hands of her parents. We might term this hypothesis $A$, where the history of the case indicates that the child's needs for protection and care would be best met in foster care.

These 'child protection' priorities are not shared to the same extent by the three fifths of respondents who decide that Dana should remain in the care of her parents. There appear to be two working hypotheses underpinning the decisions of these respondents. The first of these are represented by hypothesis $B$, where the history indicates that the child's needs would be better met by remaining at home. This 'kinship defence' position may be seen to privilege the stability of the family and mandate the state to provide supportive services.

The third discernible hypothesis $(\mathrm{C})$ is what we might term a "hedged position' on calculation of risk being subject to further assessment as to the possible effects of actions (including service inputs). This position reflects something of the tension between the child's right to family life and their right to be protected from maltreatment.

When we move to the second decision making point, however, the maintenance of the status quo of Dana remaining in foster care, supported by $94 \%$ 
of respondents, represents a shift from hypothesis $C$. The natural experiment created by two years in foster care resulting in opportunity to further evaluate the lack of progress of parents contrasting with the gains made by Dana. Choices are now seen to consolidate around hypothesis A, with parents' lack of engagement seen as confirmative of child protection concerns. Hypothesis B continues to be represented in respondents' thinking, but only in consideration of the continued rights of the family being now described in terms of contact arrangements rather than residency.

\section{Confirmation Bias}

Confirmation bias theory offers further insight into how the respondents dealt with the manipulated variables. In the case of the mother's agreement to have Dana removed to foster care we see this reinterpreted (by respondents recommending that Dana remain at home) as indicative of 'parental co-operation' and therefore predictive of better outcomes in terms of the families future willingness to receive services and benefit from them. With regard to Dana's wish to either stay in foster care or to return home; respondents tended to validate the former as insightful as to what was best for her, whilst undermining the validity of the later with respect to her competence being restricted by developmental stage. The hedged position, which makes further action consequent on reaction to past action, may be read as a provisional approach to evidence, where potentially more than one outcome is possible. While we might interpret the hedged position as reflective of a balanced approach to the issues raised in the case study, indicative of an even handed consideration of the variables; there are risks inherent in this position. We know, for 
example, that leaving children too long in situations where their needs are not being adequately met may compromise their future outcomes to a greater degree than might have been the case if the intervention had been early and decisive.

The research reported in this paper demonstrates the importance of analysing the a priori assumptions that cause professionals to develop, sometimes unconsciously, working hypotheses, which then cause them to selectively use case histories in ways which may confirm their own biases. The analysis also draws our attention to the need for researchers, when conducting primarily quantitative studies, to seek further data where possible, to illuminate statistical results with qualitative findings. Whilst quantitative research may tell us what decisions are made, it is also vital to understand why they are made.

\section{Limitations}

The findings reported here reflect the complexity of decision making by professionals but do not, in the use of a case vignette, replicate the conditions that pertain in practice, where other conditions will apply. The findings of the study are also limited by the degree of sensitivity of the researchers in relation to our consideration of qualitative data. Such interpretation is not 'value free' and there is the potential to introduce bias to the process of coding, elucidation of themes and drawing meanings of wider import from these. Finally, whilst the concept of 'confirmation bias' is well established in the literature, its particular representation in this study is bound, as ever, by the contexts of time and culture. These may have the effect of limiting the generalisability, if not of the concept, then its particular 
representation in the field of decision making in cases of child abuse and neglect as found in this study.

\section{References}

Benbenishty et al. (2014) currently under review.

Brandon, M., Bailey, S., Belderson, P., Gardner, R., Sidebotham, P., Dodsworth, J., Warren, C., \& Black, J. (2009). Understanding Serious Case Reviews and Their Impact: A Biennial Analysis of Serious Case Reviews 2005-2007. London: Department for Education.

Brannan, J. (2014). Generic Issues in Assessment and Managing Uncertainty. In J. Lishman, C. Yuill, J. Brannan, \& Gibson, A. (Eds.). Social Work: An Introduction. London: Sage.

Burton, S. (2009). The Oversight and Review of Cases in the Light of Changing Circumstances and New Information: How do People Respond to New (and Challenging) Information? London: Centre for Excellence and Outcomes in Children and Young People's Services (C4EO).

Collins, E., \& Daly, E. (2011). Decision Making and Social Work in Scotland: The Role of Evidence and Practice Wisdom. Glasgow: Institute for Research and Innovation in Social Services (IRISS).

Commission on Funding of Care and Support (2011). Fairer Care Funding. London: Department of Health.

Croisdale-Appleby, D. (2014). Re-visioning social work education: an independent review. London: Department of Health.

Davies, P. (2011). The Impact of a Child Protection Investigation: A Personal reflective Account. Child and Family Social Work, 16 (2), 201-209.

Department of Health (1998). The Quality Protects Programme: Transforming Children's Services. LAC(98)28. London: Department of Health.

Devaney, J. (2004). Relating Outcomes to Objectives in Child Protection. Child \& Family Social Work, 9(1), 27-38. 
Fox Harding, L. (1997). Perspectives in child care policy. Harlow: Addison-Wesley Longman.

Gambrill, E. (2005). Decision Making in Child Welfare: Errors and Their Context.

Children \& Youth Services Review, 27 (4), 347-352.

Giovannoni, J., \& Becerra, R. (1979). Defining child abuse. New York: The Free Press.

Grimmer, J., \& Stewart, B. (2013). The Promise and Pitfalls of Automatic Content Analysis Methods for Political Texts. Political Analysis, 21(3), 267-297.

Haringey Local Safeguarding Children Board (2009). Serious Case Review: Baby Peter - Executive Summary. London: Haringey Children's Services Department.

Hayes, D. \& Spratt, T. (2009). Child welfare interventions: Patterns of social work practice. British Journal of Social Work, 39(8), 1575-97.

Hayes, D. \& Spratt, T. (2014). Child welfare as child protection then and now: What Social Workers did and continue to do. British Journal of Social Work, 44 (3), 615635.

Helm, D. (2010). Making Sense of Child and Family Assessment: How to Interpret Children's Needs. London: Jessica Kingsley.

Holland, S. (2011). Child and Family Assessment in Social Work Practice (Second Edition). London: Sage.

Laming, H. (2009). The Protection of Children in England: A progress report. London: The Stationery Office.

McSherry, D., Weatherall, K., Fargas Malet, M., Larkin, E., \& Kelly, G. (2010). Who goes where? Young children's pathways through care in Northern Ireland. Adoption \& Fostering Journal, 34(2), 23-37.

Munro, E. (2008). Effective Child Protection (Second Edition). London: Sage.

Munro, E. (2011). The Munro Review of Child Protection - Final Report: A Child

Centred System. London: Department for Education.

Narey, M. (2014). Making the education of social workers consistently effective.

London: Department for Education.

Nickerson, R. (1998). Confirmation Bias: A Ubiquitous Phenomenon in Many Guises. Review of General Psychology, 2 (2), 175-220. 
O'Connor, L., \& Leonard, K. (2013). Decision making in children and families social work: the practitioner's voice. British Journal of Social Work. Advance access version first published online: March 19, 2013.

O'Sullivan, T. (2011). Decision Making in Social Work (Second Edition). Basingstoke: Palgrave MacMillan.

Platt, D. (2006). Investigation or initial assessment of child concerns? The impact of the refocusing initiative on social work practice. British Journal of Social Work, 36(2), 267-81.

Potter,W. J., \& Levine-Donnerstein, D. (1999). Rethinking validity and reliability in content analysis. Journal of Applied Communication Research, 27, 258-284. Reder, P., \& Duncan, S. (2004). Making the Most of the Victoria Climbié Inquiry Report. Child Abuse Review, 13 (2), 95-114.

Scott, D. (1998). A Qualitative Study of Social Work Assessment in Cases of Alleged Child Abuse. British Journal of Social Work, 28 (1), 73-88.

Spratt, T. (2000). Decision making by senior social workers at point of first referral. British Journal of Social Work, 30(5), 597-618.

Taylor, B. (2010). Professional Decision Making in Social Work Practice. Exeter: Learning Matters.

Taylor, B. (2006). Factorial Surveys Using Vignettes to study Professional Judgement. British Journal of Social Work, 36(7), 1187 - 1207. Thorpe, D., Denman, G., \& Regan, S. (2011). The Yorkshire and Humber ADCS Safeguarding and Promoting Welfare Research Project. Yorkshire and Humber: Association of Directors of Children's Services. Turney, D., Platt, D., Selwyn, J., \& Farmer, E. (2012). Improving Child and Family Assessments: Turning Research Into Practice. London: Jessica Kingsley. 